\title{
Estado imune contra o vírus vacinal (17D) da febre amarela em duas populações do Estado da Bahia
}

\author{
Immunity against yellow fever vaccinal virus (17D) in \\ two population of the Bahia State, Brazil
}

\section{Sandro Santos-Torres, Andrea Straatmann, Karla Mota, Pedro F.C. Vasconcelos, Amélia P.A. Travassos da Rosa e José Tavares-Neto}

Resumo A ocorrência de casos de febre amarela (FA) e a ampla distribuição do A. aegypti no Brasil, motivou o estudo da estimativa da proteção imune contra o vírus amarílico vacinal (17D) em moradores de duas cidades do Estado da Bahia, Ipupiara $(n=461)$ e Prado $(n=228)$. Nesta área não-endêmica de FA, a pesquisa de anticorpos séricos contra o 17D (Ac17D) e contra 18 outros arbovírus, foi realizada pelo método da inibição da hemaglutinação $(I H)$. Somente 1,2\% (8/689) dos indivíduos apresentaram Ac17D, sendo seis com resposta monotípica. A resposta sorológica do tipo heterotípica para Flavivírus (FLV) foi interpretada também como associada à resposta imune ao $17 D$, sendo mais freqüente em Prado (30,3\%) do que em Ipupiara (23,2\%). A idade $\geq 50$ anos e moradia em outros Estados foram associadas com a soropositividade para FLV, do mesmo modo que a história de vacinação (17D). Mas, a história de vacinação apresentou baixos percentuais de sensibilidade ( $\{45,4 \%)$ e de valor preditivo-positivo $(\leq 38,4 \%)$, sendo altos os valores da especificidade ( $\geq 70,8 \%$ ) e do valor preditivo-negativo ( $\geq 78,8 \%)$. Em conclusão, foi baixa a freqüência $(1,2 \%)$ de moradores com Ac17D, apesar da freqüência maior $(25,5 \%)$ de portadores de anticorpos $F L V$, o que significa que $26,7 \%$ da população estudada pode apresentar proteção contra o vírus da FA.

Palavras-chaves: Vacina 17D. Febre amarela. Soroprevalência. Bahia.

Abstract The occurrence of cases of yellow fever (YF) and also the extensive distribution of A. aegypti in Brazil, inspired a study about the estimate of immunity against vacinal virus (17D) among the residents at two cities of the Bahia state, Ipupiara $(n=461)$ and Prado $(n=228)$. At this non-endemic area of YF, the search for serology antibody against 17D (Ab17D) and 18 another arbovirus was made thereby hemagglutination inhibition (HI). Only 1.2\% (8/689) showed $A b 17 D$, six of those with monotypic sort. The heterotypic sort for flavivirus (FLV) was interpretted as associated to immunity against $17 D$ too, being much frequent in Prado (30.3\%) than in Ipupiara (23.2\%). The age $\geq 50$ years and residence in another states were related to seropositive for $F L V$, the same way that vaccination's history $(17 D)$. Howener, the history of vaccination presented low percentages of sensibility ( $\leq 45.4 \%)$ and predictive-positive value (£38.4\%), but high specificity $(\geq 70.8 \%)$ and predictive-negative value $(\geq 78.8 \%)$. Therefore, the frequency of residents with $A b 17 D$ was low (1.2\%), althoug the higher frequency (25.5\%) of antibody FLV carrier's, what signifies that $26.7 \%$ of the studied population should present protection against the YF virus.

Key-words: Vaccine 17D. Yellow fever. Seroprevalence. Bahia State.

\footnotetext{
Faculdade de Medicina da Universidade Federal da Bahia, Salvador, BA e Instituto Evandro Chagas, Belém, PA. Fontes de Apoio e Financiamento: PET-Medicina (CAPES/UFBA)e CNPq/FNS (proc. 52.0173/97-0).

Endereço para correspondência: Dr. José Tavares-Neto. Hospital Universitário Prof. Edgard Santos. Campus UFBA do Canela. 40110-160 Salvador, BA.

Telefax: $5571247-4391$

E-mail: tavaneto@ufba.br

Recebido para publicação em 22/10/98.
} 
A disseminação do Aedes aegypti no Brasil criou as condições necessárias para a reurbanização do vírus da febre amarela ${ }^{816}$, inclusive devido as facilidades atuais de transporte entre regiões distantes ${ }^{6}$. A febre amarela silvestre é freqüentemente descrita no $\mathrm{Brasil}^{324}$ e os casos silvestres, diagnosticados no segundo trimestre de 1998 nos Estados do Pará, Amazonas e Roraima (Travassos da Rosa APA: comunicação pessoal), reforçam, mais ainda, a relevância de se estudar e traçar estratégias sobre a necessidade de vacinar a população brasileira.

Entre as medidas de prevenção da infecção pelo vírus da febre amarela (Flaviviridae), a vacinação é uma das mais eficientes e que confere proteção a partir do décimo dia, durando pelo menos 10 anos ${ }^{4}{ }^{14}$, sendo encontrada proteção, em alguns casos, por mais de três décadas e com uma única dose da vacina antiamarílica ${ }^{141521}$. Entre as vacinas usadas, aquela obtida a partir da atenuação da cepa selvagem Asibi que originou a cepa 17D tem sido largamente aplicada desde o final da década de 30 com raros casos de reações adversas graves, pois é desprovida habitualmente de neuro e viscerotropismo ${ }^{11} 17$

No Brasil, o programa de vacinação com o vírus 17D foi aplicado até o início dos anos 60 em grande número de populações do território nacional ${ }^{12}$, inclusive do Estado da Bahia ${ }^{21}$. A partir da década de 70 , esse programa de vacinação ficou quase que restrito aos moradores, viajantes e trabalhadores das regiões Norte e Centro-Oeste do país, áreas endêmicas da febre amarela silvestre. Todavia, no final dos anos 80 , especialmente devido as epidemias de febre amarela silvestre naquelas regiões brasileiras e também com a reintrodução do $A$. aegypti, o programa de vacinação foi ampliado com a colocação de barreiras rodoviárias com vacinadores, principalmente nas cidades próximas às fronteiras dos Estados de Goiás, Mato Grosso, Tocantins e Pará4.

No Estado da Bahia, ocorreu no primeiro semestre de 1987, epidemia de dengue pelo sorotipo 1, limitada à área urbana da cidade de Ipupiara ${ }^{9}$. No final do quarto trimestre de 1994 foi introduzido no Estado o sorotipo $2^{13}$, a partir da região do extremo sul e na mesma região o sorotipo 1 voltou a circular no Estado em $1996^{9}$. A expansão da epidemia de dengue no Estado da Bahia atingiu populações de diferentes portes devido a ampla distribuição do $A$. aegypti. Em vista disso, o objetivo foi investigar a história de vacinação contra a febre amarela e o estado imune contra o vírus vacinal 17D de moradores de duas cidades do Estado da Bahia.

\section{MATERIAL E MÉTODOS}

As populações de duas cidades do Estado da Bahia foram selecionadas para o estudo de soroprevalência: a) Ipupiara, na região da Chapada Diamantina (região central do Estado) e distante $624 \mathrm{~km}$ de Salvador, capital do Estado e b) Prado, cidade litorânea, na região do extremo sul, distando $787 \mathrm{~km}$ de Salvador. As cidades selecionadas, e as respectivas regiões, apresentam entre si marcantes diferenças históricas, sócioculturais, econômicas e antropológicas.

O estudo seccional foi realizado nas cidades de Ipupiara e do Prado, respectivamente, de 22 a 30 de julho e de 18 a 22 de dezembro de 1995. Nestes dois municípios, os moradores (presentes no momento da visita domiciliar) maiores de 7 anos de idade do primeiro e do décimo domicílio, de cada quadra da área urbana foram incluídos no estudo. Na amostra de Ipupiara, outros critérios de inclusão foram a residência na localidade durante o primeiro semestre de 1987 e data de nascimento até 31 de dezembro de 1986.

Em ambas as cidades, a coleta de informações demográficas e de sangue foram realizados nos domicílios dos indivíduos amostrados. As amostras sangüíneas foram obtidas após o consentimento de cada indivíduo. As informações individuais foram anotadas em questionário-padrão, no momento da coleta da amostra sangüínea, tais como: sexo, idade (extraída de documento de identidade), viagens (ou residências) para outros Estados do Brasil e história de vacinação antiamarílica. No levantamento desta última informação, as condições (ano, local e a razão da vacinação) e a apresentação da carteira de vacinação (ou outro documento comprobatório) foram também investigadas.

A pesquisa de anticorpos contra o vírus vacinal da febre amarela (17D) foi realizada por meio do microteste de inibição da hemaglutinação $(\mathrm{IH})^{181923}$, usando soros-controles reconhecidamente negativos e positivos do Instituto Evandro Chagas (IEC) de Belém, Pará. A cepa viral (17D) utilizada é mantida no Laboratório de Arbovírus do IEC por passagens sucessivas em camundongos récem-nascidos, bem como as demais cepas 
virais testadas de: Flavivirus (dengue [1, 2, 3 e 4], Rocio, Ilhéus, febre amarela selvagem e St. Louis); Alphavírus (Mucambo, Mayaro, encefalite eqüina do leste e oeste) e Bunyavírus (Oropouche, Guaroa, Caraparu, Catu, Tacaiuma, Maguari). Pelo teste de $\mathrm{IH}$, o soro foi considerado positivo quando o título era igual ou superior a 20.

Os indivíduos primo-vacinados com a cepa 17D desenvolvem, por tempo prolongado, anticorpos neutralizantes $(\mathrm{N})$ e inibidores da hemaglutinação (IH), especialmente os primeiros ${ }^{715}$. Porém, a resposta imune com anticorpos $\mathrm{IH}$, habitualmente, é do tipo gênero-específica, heterotípica e em conseqüência as reações cruzadas com outros Flavivirus são freqüentes ${ }^{522}$. Contudo, devido ao menor custo e a maior rapidez do teste de $\mathrm{IH}$, comparado com o teste de neutralização, o teste de IH é indicado em estudos soro-epidemiológicos ${ }^{22}$. Assim, pelo teste de $\mathrm{IH}$, as respostas heterotípicas para Flavivírus são consideradas como provável resposta sorológica à cepa vacinal $17 D^{522}$. Desse modo, neste estudo os indivíduos soropositivos para o vírus vacinal 17D foram considerados aqueles com anticorpos IH antiFlavivirus (resposta heterotípica) ou com resposta monotípica (reação anti-17D específica).

As diferenças observadas nos testes estatísticos foram consideradas significativas quando a probabilidade $(p)$ do erro tipo I $(\alpha)$ foi inferior ou igual a $5 \%(p \leq 0,05)$.

\section{RESULTADOS}

No total foram estudados 689 moradores, sendo 461 da cidade de Ipupiara e 228 da cidade de Prado. Somente 1,2\% $(n=8)$ dos indivíduos testados apresentaram resposta sorológica $(\mathrm{IH})$ contra o vírus vacinal $17 \mathrm{D}$ e a freqüência de soropositivos foi semelhante (teste exato de Fisher $p>0,53$ ) entre os indivíduos da cidade de Ipupiara (5/461) e do Prado (3/228), respectivamente $1,1 \%$ e $1,3 \%$. Entre essas amostras séricas soropositivas, seis foram respostas monotípicas e duas heterotípicas (também soropositivas para o Dengue-2 e ambas de Prado).

A presença de resposta heterotípica de anticorpos $\mathrm{IH}$ para dois ou mais dos Flavivirus testados, e mais para o 17D, foi observada em $178(25,5 \%)$ amostras séricas. Entre esses soros, $23,6 \%$ (109/461) procediam de Ipupiara e 30,3\% (69/228) de Prado, sendo essa diferença de positividade estatisticamente significante $\left(\chi^{2}=\right.$ $3,99 ; \mathrm{p}<0,05)$. Esses indivíduos $(\mathrm{n}=178)$ somados aos de resposta monotípica $(n=6)$ elevou a freqüência geral de soropositivos contra o 17D para $26,7 \%$ (184/689).

A história de vacinação contra o vírus da febre amarela foi referida por $21,8 \%(n=150)$ da população estudada, sendo as freqüências muito diferentes $\left(\chi^{2}=10,65, p<0,001\right)$ entre a da cidade de Ipupiara e a de Prado, respectivamente $25,4 \%$ (117/461) e 14,5\% (33/228). No grupo com história de vacinação, a quase totalidade $(n=148)$ relatou que a vacina 17D foi aplicada por ocasião de viagens em postos da SUCAM, localizados em barreiras rodoviárias; somente dois (ambos sabiam o ano da vacinação e foram soropositivos), usaram a vacina na sede da SUCAM. No grupo com história de vacinação $(n=150), 97$ indivíduos $(64,7 \%)$ desconheciam ou não sabiam localizar a carteira de vacinação, bem como não sabiam referir o ano da vacinação.

Os outros 53 (35,3\%) indivíduos com informação sobre o ano de vacinação, também desconheciam ou não sabiam localizar a carteira de vacinação. Nesse grupo $(n=53)$, dois foram vacinados respectivamente em 1959 e 1975 , outros 35 foram vacinados entre 1983 a 1989 e os demais $(n=16)$ no período de 1990 a 1995. Porém, a maioria $(58,5 \%)$ dos indivíduos foi vacinada $(n=31)$ no período de 1986 a 1989. As freqüências de soropositivos (antiFlavivírus + 17D) foram analisadas conforme o período da vacinação, nas três classes intervalares estudadas (1959 $1985 ; 1986|-| 1989$ e $1990|-| 1995)$ e foram, respectivamente: $33,3 \%(2 / 6) ; 41,9 \%(13 / 31)$ e $50,0 \%$ (8/16); porém, a análise dessas proporções mostrou que eram estatisticamente semelhantes ( $p>0,45)$, mesmo quando se comparou as freqüências de soropositivos dos dois períodos extremos (teste exato de Fisher: $p>0,41$ ). A comparação das freqüências de soropositivos que informaram $(43,4 \%)$ o ano de vacinação (23/ 53) com aqueles que não conheciam essa informação $(36,1 \%$; 35/97), foi estatisticamente semelhante $\left(\chi^{2}=0,77 p>0,37\right)$.

Na Tabela 1, a soropositividade foi apresentada conforme a cidade de procedência da amostra, considerando somente a história de vacinação ou não. Na população de Ipupiara a distribuição foi altamente desigual ( $p<0,0003)$, por conta do excesso de soropositivos $(n=43)$ entre os indivíduos com história de vacinação correspondendo a $56,8 \%$ do qui-quadrado total. 
A mesma tendência foi observada entre os moradores de Prado, mas sem alcançar significância estatística $(p>0,07)$. Também a Tabela 1 mostra que a história de vacinação teve baixa sensibilidade (36,8\% Ipupiara e 45,4\% Prado) e especificidade (79,9\% Ipupiara e $88,5 \%$ Prado), sendo os valores preditivos-positivos baixos $(38,4 \%$ Ipupiara e $20,8 \%$ Prado) e preditivos-negativos altos $(78,8 \%$ Ipupiara e $70,8 \%$ Prado). Todavia, a concordância da história de vacinação e o resultado da sorologia foi semelhante $\left(\chi^{2}=0,25 ; p>0,61\right)$ entre Ipupiara $[(53+275) / 461=69,0 \%]$ e Prado $[(15+138) / 228$ $=67,1 \%]$. Ou analisando de outro modo, as proporções de classificação incorretas (discordantes), como mostrado na Tabela 1, observadas nos moradores das duas cidades foram também semelhantes $\left(\chi^{2}=0,25 ; p>0,61\right)$. Porém, a medida da confiabilidade do instrumento (história de vacinação) apresentou índice Kappa pequeno $(<0,20)$, em Ipupiara $(\mathrm{K}=0,17)$ e Prado $(\mathrm{K}=0,11)$.

Tabela 1 - História de vacinação contra a febre amarela (17-D) na população de duas cidades, do Estado da Bahia, segundo o resultado da sorologia $(I H)$.

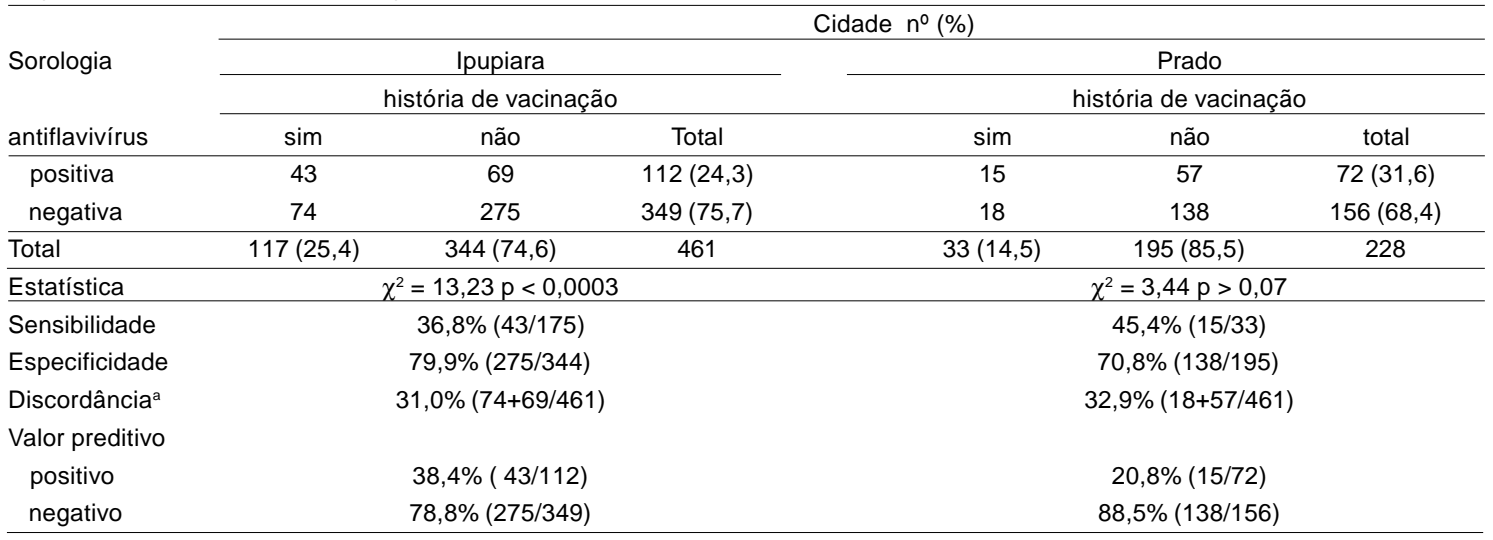

(a) ou proporção de classificação incorreta

$\mathrm{Na}$ Tabela 2, foram mostradas as características demográficas dos indivíduos pesquisados. Quanto ao gênero, em Ipupiara $\left(\chi^{2}\right.$ $=0,26 ; p>0,60)$ e em Prado $\left(\chi^{2}=2,0 ; p>0,15\right)$, as freqüências de soropositivos foram semelhantes. Em ambas as cidades, a mediana da idade dos soropositivos foi - a 50 anos e a dos soronegativos • a 31 anos, sendo as médias das idades dos soropositivos e soronegativos muito diferentes (Ipupiara: $t=6,44 ; p<0,0001$; Prado: $t=6,49 p<0,0001)$. O relato de residência ou viagens para outro(s) Estado(s) do país, de uma ou mais região, foi muito mais freqüente entre soropositivos de Ipupiara $\left(\chi^{2}=25,62 p<0,000001\right)$, não sendo observada diferença nos indivíduos procedentes de Prado $\left(\chi^{2}=0,02 p>0,80\right)$.
O relato de viagens e residência dos moradores de Ipupiara (14,5\%;67/461) foi duas vezes maior do que o dos moradores de Prado $(7,0 \% ; 16 / 228)$, sendo a diferença estatisticamente significante $\left(\chi^{2}=8,14 p<0,005\right)$. A distribuição do relato de residência ou viagem, segundo o sexo, foi semelhante nos indivíduos procedentes de Ipupiara $\left(\chi^{2}=0,38 p>0,53\right)$ e Prado $\left(\chi^{2}=2,35\right.$ $\mathrm{p}>0,12)$. Na cidade de Prado, as médias das idades, dos indivíduos com relato de residência ou viagem para outro Estado $(42,83 \pm 14,70$ anos) e sem relato $(44,22 \pm 19,34$ anos), foram estatisticamente semelhantes $(t=0,48 ; p>0,65)$, enquanto entre os da cidade de Ipupiara foram muito diferentes ( $t=5,42 p<0,001)$, respectivamente, $44,75 \pm 20,28$ anos e 33,94 \pm 21,36 anos. 
Tabela 2. Presença de anticorpos (IH) contra o vírus vacinal da febre amarela (17D) ou de resposta heterotípica antiFlavivírus em moradores de duas cidades do Estado da Bahia, associada à idade, gênero e residência/viagem para outros estados.

\begin{tabular}{|c|c|c|c|c|c|c|}
\hline \multirow{3}{*}{ Variável } & \multicolumn{6}{|c|}{ Sorologia } \\
\hline & \multicolumn{3}{|c|}{ Ipupiara $(n=461)$} & \multicolumn{3}{|c|}{ Prado $(n=228)$} \\
\hline & $\mathrm{n}^{0}$ & $\%$ & $t$ & $\mathrm{n}^{0}$ & $\%$ & $t$ \\
\hline \multicolumn{7}{|l|}{ Gênero } \\
\hline feminino & 64 & 23,4 & 273 & 42 & 28,4 & 148 \\
\hline masculino & 48 & 25,5 & 188 & 30 & 37,5 & 80 \\
\hline \multicolumn{7}{|c|}{ Contato com outros estados } \\
\hline não & 45 & 16,1 & 279 & 56 & 31,8 & 176 \\
\hline $\operatorname{sim}$ & 67 & 36,8 & 182 & 16 & 28,6 & 52 \\
\hline \multicolumn{7}{|l|}{ Idade (anos) } \\
\hline \multicolumn{7}{|l|}{ Soropositivos } \\
\hline $\mathrm{n}$ & 112 & & & 72 & & \\
\hline limites & $9|æ| 90$ & & & $8|æ| 94$ & & \\
\hline mediana & 50 & & & 54 & & \\
\hline média & 49,16 & & & 54,60 & & \\
\hline desvio padrão & 20,08 & & & 18,60 & & \\
\hline \multicolumn{7}{|l|}{ Soronegativos } \\
\hline $\mathrm{n}$ & 349 & & & 156 & & \\
\hline limites & $9|æ| 89$ & & & $8|æ| 95$ & & \\
\hline mediana & 31 & & & 35 & & \\
\hline média & 34,69 & & & 38,97 & & \\
\hline desvio padrão & 20,87 & & & 16,06 & & \\
\hline
\end{tabular}

\section{DISCUSSÃO}

Em 1984, antes, portanto, da primeira epidemia ocasionada pelo vírus do dengue no Estado da Bahia ocorrida em $1987^{9}$, somente $1 \%$ dos indivíduos testados do povoado de Corte de Pedra (Bahia) apresentou anticorpos ( $\mathrm{IHe} \mathrm{N}$ ) contra o vírus 17D 21 , freqüência semelhante às observadas em Ipupiara $(1,1 \%)$ e Prado $(1,3 \%)$, considerando as respostas monotípicas (17D) e DEN-1 + 17D.

A resposta sorológica heterotípica para Flavivírus associada à vacinação anti-amarílica ${ }^{522}$, foi observada em $25,5 \%$ dos indivíduos estudados. Uma hipótese para explicar esse tipo de resposta sorológica seria a exposição contínua à infecção por outros Flavivirus ${ }^{7}$ no Estado da Bahia, como Rocio e llhéus porém não houve evidências nesse sentido no trabalho em discussão. Em 1984, antes da circulação mais recente dos vírus do dengue no Estado da Bahia, somente 2,1\% e 0,7\% dos moradores de Corte de Pedra eram portadores de anticorpos $\mathrm{N}$, respectivamente, contra os Flavivirus Ilhéus e St. Louis ${ }^{21}$. Anteriormente, Niederman e cols ${ }^{10}$ estudaram amostras séricas de recrutas nordestinos, de procedência variada (segundo o local da instituição militar), sem história de vacinação antiamarílica (17D) e encontraram que $12,4 \%$ eram portadores de anticorpos $\mathrm{N}$ antiFlavivírus (Ilhéus e St. Louis). Mais recentemente, as freqüências de portadores de anticorpos IH antiFlavivírus (Ilhéus, St. Louis e febre amarela) foi nula ou inferior a $1 \%$ em Ipupiara ${ }^{9}$ e Prado (dados não-publicados). Quanto ao Flavivirus Rocio a freqüência de portadores de anticorpos IH e/ou $\mathrm{N}$ em três localidades do Estado da Bahia foi também inferior a $1 \%{ }^{20}$.

As características ecológicas dos municípios de Ipupiara e Prado são muito diferentes. No primeiro, predomina a vegetação de caatinga e o clima é seco com períodos prolongados de estiagem. No segundo, a sede do município é a beira-mar, o clima é úmido e há áreas de mangue, mata atlântica e de reflorestamento industrial. Nessas condições, a circulação de arbovírus seria mais propícia na área do município de Prado, no entanto, como assinalado acima, as freqüências de portadores de anticorpos $\mathrm{IH}$ contra os Flavivírus, inclusive o Rocio ${ }^{20}$, e outros arbovírus (Alfavirus e Bunyavirus) estudados foram inferiores a $1 \%$. 
Como a circulação do sorotipo dengue- 1 foi interrompida em Ipupiara em 1987, por meio de ações associadas ao plano de erradicação do $A$. aegypt ${ }^{\dagger}$, a presença de imunidade para arbovírus para os moradores de Ipupiara, a hipótese de que as características ecológicas distintas seria fator relevante para adquirir esses anticorpos não tem sustentação. Por outro lado, na cidade de Prado circulou de forma epidêmica, até próximo à época do estudo (dezembro de 1995), o dengue- $2^{13}$, o quê em parte poderia explicar a freqüência maior de portadores (respondedores heterotípicos) de anticorpos antiFlavivírus $(30,3 \%)$, superior a freqüência observada em Ipupiara $(23,2 \%)$. Isto ocorreu, provavelmente, porque a infecção recente por Flavivírus em indivíduos previamente vacinados (17D) aumenta a freqüência da resposta sorológica do tipo heterotípica?.

Paradoxalmente, a freqüência de indivíduos com relato de vacinação antiamarílica em Prado $(14,5 \%)$ foi muito inferior $(p<0,001)$ da observada em Ipupiara $(25,4 \%)$. Isto provavelmente se explica porque a quase totalidade $(98,7 \%)$ dos vacinados relataram o uso da vacina (17D) em postos móveis (de barreiras rodoviárias) e como a mobilidade da população de Ipupiara é maior, o relato de vacinação foi também proporcionalmente maior. Desde quando na população estudada de Ipupiara, $14,5 \%$ relataram viagem para ou residência em cidades de outros estados, significativamente maior $(p<0,005)$ ao relato semelhante em Prado (7\%). Essa menor mobilidade da população estudada de Prado é decorrente, muito provavelmente, da melhor situação econômica e de indicadores de desenvolvimento humano do município ${ }^{2}$, ao contrário da população de Ipupiara exposta a constantes períodos de seca, obrigando-a a buscar trabalho em outros Estados. Talvez, por isto, em Prado as médias de idade dos indivíduos, de ambos os sexos, com ou sem relato de moradia em outros Estados foram semelhantes, evidenciando algum equilíbrio demográfico. Já em Ipupiara a idade média dos indivíduos, de ambos os sexos, com relato de residência em outros Estados foi maior, podendo significar a busca de mercado de trabalho. Por sua vez, os resultados observados em Prado (menor freqüência de vacinados e a maior freqüência de soropositivos), reforçam a suposição anterior que a circulação do dengue-1 tenha provocado o aumento da freqüência de resposta heterotípica nos indivíduos vacinados (17D).
Os indivíduos soropositivos (17D) com resposta heterotípica ou não, de ambas as cidades, apresentaram média de idade maior. Esse resultado pode significar maior exposição ao vírus vacinal 17D ao longo da vida ou durante as campanhas de vacinação antes dos anos sessenta ${ }^{21}$. Como os indivíduos mais idosos de Ipupiara relataram maior mobilidade, provavelmente foram mais expostos ao programa de prevenção ativa e conseqüentemente a freqüência de soropositivos foi maior entre eles. Ao contrário, na população de Prado a freqüência do relato de viagens e/ou residência para outros estados foi semelhante entre os soropositivos e soronegativos, reforçando a suposição que esse relato não esteja vinculado à busca de mercado de trabalho, mas devido à proximidade com grandes cidades da região sudeste. Desse modo, os indivíduos de Prado, independente da idade, viajam para outros estados por motivos diversos, inclusive turismo.

No entanto, apesar das diferenças entre as duas populações estudadas, a história de vacinação como instrumento de avaliação tem confiabilidade pequena $(K<0,20)$ em ambas populações. Esse instrumento é muito sujeito à recordação de cada indivíduo estudado, podendo ser causa de viés relevante; exemplo disso, foi o achado que $64,7 \%$ dos indivíduos não sabiam referir o ano da vacinação (17D). Outra possibilidade de erro, não estudada, e freqüentemente relatada, foi o indivíduo (ou familiar responsável) confundir a vacina 17D com outras vacinas, inclusive com a vacina oral antipólio. Por essa razão o melhor instrumento para avaliar a história de vacinação seria a apresentação de carteira de vacinação ou outro documento comprobatório fornecido pela instituição responsável pela aplicação da vacina. No entanto, mesmo tendo sido as informações levantadas no domicílio de cada indivíduo estudado, a totalidade não tinha ou não localizou nenhum documento que comprovasse a vacinação e somente $35,3 \%$ sabiam referir o ano da vacinação. Situação semelhante foi observada em um estudo de 1.944 escolares de Uberlândia (MG), de 7 a 14 anos de idade. Nesse estudo, 71,9\% $(n=1.397)$ de estudantes não tinham cartão de imunizações, concluindo os autores ${ }^{1}$ que uma das prováveis razões é a falta de programa educativo eficiente.

Apesar da falta de dados objetivos sobre a história de vacinação, coerentemente, a maioria dos indivíduos do grupo com relato sobre o ano de vacinação, o período (1986 a 1989) de maior 
freqüência $(58,5 \%)$ coincide com o período de intensificação da instalação de postos móveis em rodovias, especialmente às de ligação com as regiões norte e centro-oeste (Fundação Nacional de Saúde: dados não-publicados).

Em conseqüência da baixa circulação de Flavivirus no Estado da Bahia, das diferentes épocas e sorotipos circulantes do vírus do dengue nas duas cidades, da baixa sensibilidade e confiabilidade da história de vacinação não há outra explicação com base nos dados estudados, senão a vacinação prévia com o $17 \mathrm{D}$, para o encontro de freqüências elevadas de resposta sorológica heterotípica nos indivíduos sem relato de vacinação (20,0\% em Ipupiara e $29,2 \%$ em Prado).

Entretanto, a história de vacinação por ter especificidade de moderada $(70,8 \%)$ a elevada $(79,9 \%)$, distingue os verdadeiros soronegativos, o quê pode ser útil em programas extensos de vacinação, especialmente existindo falta de recursos humanos e/ou materiais.

Como as prevalências de soropositivos (resposta heterotípica e monotípica) foram diferentes em cada cidade (Ipupiara: $24,3 \%$ e Prado: $31,6 \%$ ), na validação do instrumento (história de vacinação) os valores preditivos são mais adequados. Desse modo, os valores preditivos-negativos elevados, de Ipupiara $(78,8 \%)$ e Prado $(88,5 \%)$, evidenciam mais ainda o poder do instrumento de distinguir os verdadeiros-soronegativos. Ao contrário, os valores preditivos-positivos foram baixos, mostrando que a probabilidade do instrumento distinguir os verdadeiros-soropositivos tem baixa validade. Deve-se reiterar que tais informações podem ser úteis no planejamento de programas vacinais para população de maior porte.
Por outro lado, os baixos valores preditivospositivos observados (38,4\% Ipupiara e $20,8 \%$ Prado) também levantam suspeitas sobre a ocorrência de outros eventos, desde a ausência de resposta sorológica individual às deficiências na conservação e aplicação da vacina 17D. Em escolares de Bocaiuva, Minas Gerais, Guerra e cols $^{4}$ encontraram $17 \%$ de vacinados sem anticorpos neutralizantes (N), enquanto $9 \%$ dos não-vacinados tinham anticorpos $\mathrm{N}$ anti-17D. Estes resultados ${ }^{4}$ também reforçam os baixos valores observados de sensibilidade e preditivopositivo, da história prévia da vacinação.

Em conclusão, foi baixa a freqüência de portadores de anticorpos IH anti-17D, especialmente porque, nas populações estudadas, não houve nas quatro últimas décadas nenhum programa de proteção vacinal contra a febre amarela. Assim, considerando a cobertura vacinal nesses municípios, a freqüência de portadores de anticorpos IH antiFlavivírus em Ipupiara (24,3\%) e Prado $(31,6 \%)$ pode ser considerada elevada e, embora não signifique certeza de proteção contra a febre amarela, a eventual introdução do vírus da febre amarela, nas populações estudadas, pode causar menor taxa de morbimortalidade, se parte dessa imunidade é devida à vacinação antiamarílica. Contudo, é preocupante a constatação que a totalidade dos indivíduos estudados, com história de vacinação contra a febre amarela, não dispõe de caderneta de vacinação ou outro documento comprobatório, o que pode demonstrar, muito provavelmente, a conseqüência da falta de programa de educação e informação. Situação essa que fica evidente na falta de vinculação, nas campanhas oficiais de informação sobre a epidemia de dengue, da associação do $A$. aegypti com o vírus da febre amarela, e especialmente sobre o risco de reurbanização desse vírus no Brasil.

\section{REFERÊNCIAS BIBLIOGRÁFICAS}

1. Ambrósio MR, Fernandes EC. Análise do cartão de imunizações em escolares de Uberlândia. Revista Cearense de Pediatria 1:17, 1998.

2. Barros ML, Boecken G. Jungle yellow fever in the central Amazon. Lancet 348:969-970, 1996.

3. Centro de Estatística e Informações. Classificação dos municípios baianos. Informações básicas. Secretaria de Planejamento, Ciência e Tecnologia do Governo do Estado da Bahia, vol. II, Salvador, 1997.

4. Guerra HL, Sardinha TM, Travassos da Rosa AP, Lima e Costa MF. Efetividade da vacina antiamarílica 17D: um avaliação epidemiológica em serviços de saúde. Revista Panamericana de Salud Publica 2:115-120, 1997.

5. Kayser M, Klein H, Paasch I, Pilaski J, Blenk H, Heeg K. Human antibody response to immunization with 17D yellow fever and inactivated TBE vaccine. Journal of Medical Virology 17:35-45, 1985.

6. McFarland JM, Baddour LM, Nelson JE, Elkins SK, Craven RB, Cropp BC, Chang GJ, Grindstaff AD, Craig AS, Smith RJ. Imported yellow fever in a United States citizen. Clinical Infectious Diseases 25:1143-1147, 1997.

7. Monath TP, Craven RB, Muth DJ, Trautt CJ, Calisher CH, Fitzgerald AS. Limitations of the complement-fixation test 
for distinguishing naturally acquired from vaccineinduced yellow fever infection in flavivirus-hyperendemic areas. American Journal of Tropical Medicine and Hygiene 29:624-634, 1980.

8. Mondet B, Travassos da Rosa AP, Vasconcelos PF. Les risques d'épidémisation urbaine de la fièbre jaune au Brésil. Par le vectures de la dengue Aedes aegypti et Aedes albopictus. Bulletin de la Societé de Pathologie et de ses Filiales 89:107-113, 1996.

9. Mota K. Dengue na Bahia: estudo soro-epidemiológico na população da cidade de Ipupiara. Tese de Mestrado, Universidade Federal da Bahia, Salvador, 1998.

10. Niederman JC, Henderson JR, Opton EM, Black FL, Skvrnova K. A nationwide serum survey of Brazilian military recruits, 1964. II. Antibody patterns with arboviruses, polioviruses, measles and mumps. American Journal of Epidemiology 86:319-329, 1967.

11. Nishioka AS, Nunes-Araújo FR, Pires WP, Silva FA, Costa $\mathrm{HL}$. Yellow fever vaccination during pregnancy and spontaneous abortion: a case-control study. Tropical Medicine and International Health 3:29-33, 1998.

12. Nobre A, Antezana D, Tauil PL. Febre amarela e dengue no Brasil: epidemiologia e controle. Revista da Sociedade Brasileira de Medicina Tropical 27 (supl III):59-66, 1994.

13. Nogueira RM, Miagostovich MP, Schatzmayr HG, Moraes GC, Cardoso FM, Ferreira J, Cerqueira V, Pereira M. Dengue type 2 outbreak in the South of the State of Bahia, Brazil: laboratorial and epidemiological studies. Revista do Instituto de Medicina Tropical de São Paulo 37:507510, 1995.

14. Pinheiro FP, Gomes MLC. Immune response to yellow fever vaccine. In: Symposium on yellow fever, Belém, 1980.

15. Poland JD, Calisher CH, Monath TP, Downs WG, Murphy K. Persistence of neutralizing antibody 30-35 years after immunization with 17D yellow fever vaccine. Bulletin of the World Health Organization 59:895-900, 1981.

16. Prata A, Travassos da Rosa APA, Teixeira G, Coêlho ICB, Tavares-Neto J, Dias J, Figueiredo LTM, Dietze R, Valls
R, Maris S, Alecrim W. Condutas terapêuticas e de suporte no paciente com dengue hemorrágico. Informe Epidemiológico do SUS 6:87-101, 1997.

17. Schoub BD, Dommann CJ, Jonhson S, Downie C, Patel $\mathrm{PL}$. Encephalitis in a 13-year-old boy following 17D yellow fever vaccine. Journal of Infection 21:105-106, 1990.

18. Shope RE. The use of micro-hemagglutination test to follow antibody response after arthropod-borne virus infection in a community of forest animals. Annual Review of Microbiology XI (part a):167-71, 1963.

19. Shope RE, Sather GE. Arboviruses. In: Lennette EH, Schmidt NJ (eds) Diagnostic Procedures for Viral, Rickettsial and Chlamydial Infections. American Public Health Association, Washington, p. 767-814, 1979.

20. Straatmann A, Santos-Torres S, Vasconcelos PFC, Travassos da Rosa APA, Rodrigues SG, Tavares-Neto J. Evidências sorológicas do arbovírus Rocio (Flaviviridae) na Bahia. Revista da Sociedade Brasileira de Medicina Tropical 30:511-515, 1997.

21. Tavares-Neto J, Travassos da Rosa APA, Vasconcelos PFC, Costa JML, Travassos da Rosa JFS, Marsden PD. Pesquisa de anticorpos para arbovírus no soro de residentes no povoado de Corte de Pedra, Valença, Bahia. Memórias do Instituto Oswaldo Cruz 81:351-358, 1986.

22. Theiler M, Downs WG. The arthropod-borne viruses of vertebrates. Yale University, New Haven, 1973.

23. Travassos da Rosa AP, Travassos da Rosa ES, Travassos da Rosa JF, Dégallier N, Vasconcelos PFC, Rodrigues SG. Os arbovírus no Brasil: generalidades, métodos e técnicas de estudo. Instituto Evandro Chagas, documento técnico n. 2, Belém, 1994.

24. Vasconcelos PF, Rodrigues SG, Degallier N, Moraes MA, Travassos da Rosa JF, Travassos da Rosa ES, Mondet B, Barros VL, Travassos da Rosa AP. An epidemic of sylvatic yellow fever in the Southeast region of Maranhão State, Brazil, 1993-1994: epidemiologic and entomologic findings. American Journal of Tropical Medicine and Hygiene 57:132-137, 1997. 